Check for updates

Cite this: Phys. Chem. Chem. Phys., 2019, 21, 13230

Received 29th April 2019, Accepted 20th May 2019

DOI: $10.1039 / c 9 c p 02437 a$

rsc.li/pccp

\section{Co-incorporation of alkali metal ions during amorphous calcium carbonate precipitation and their stabilizing effect $\uparrow$}

\author{
Anders C. S. Jensen, (D) ${ }^{\text {ab }}$ Henrik Birkedal (D) ${ }^{c}$ and Luca Bertinetti (D) *a
}

Calcium carbonate formation has been studied extensively due to its central role in biomineralization and geochemistry. Specifically, the effect of additives incorporated during the formation process has been described in several works related to inorganic, small organic, molecular or macromolecular additives. However, in these previous experiments the presence of counter ions and their possible role has been mostly disregarded. Co-incorporation of counter ions into calcite at low supersaturations has been studied in detail but their incorporation in and effect on the formation and stability of the amorphous phase, which precedes the formation of the crystalline phase at high supersaturations, has not been studied. To address this, we have investigated the incorporation of alkali metal ions into the amorphous phase using various carbonate salts as a carbonate source. We show that the incorporation is the highest for $\mathrm{Rb}^{+}$with the highest measured value being $5.8 \mathrm{at} \% \mathrm{Rb}^{+} /\left(\mathrm{Rb}^{+}+\mathrm{Ca}^{2+}\right)$. The extent of ion incorporation follows the ion size of $\mathrm{Rb}^{+}>\mathrm{K}^{+}>\mathrm{Na}^{+}>\mathrm{Li}^{+}$which is opposite to that observed in calcite formed at low supersaturation. The presence of these ions in the amorphous phase increases the crystallization temperature, which can be shifted by as much as $200{ }^{\circ} \mathrm{C}$ depending on the concentration of alkali metal ions incorporated. However, the lifetime of ACC in solution was similar for all the different carbonate sources.

\section{Introduction}

The effect of additives on calcium carbonate formation has been studied extensively, mostly because inorganic ions, small organic molecules and macromolecules are believed to be key to the high degree of morphological and compositional control exhibited by various calcium carbonate forming organisms. ${ }^{2,3}$ Calcium carbonate synthesis often involves simple precipitation reactions having alkali metals and halide ions as counter ions for the carbonate and calcium ions, respectively. These counter ions are often considered inactive spectator ions, but they have been shown to act as additives as seen in hydroxyapatite formation using amorphous calcium phosphate, where both crystallite size and growth rate are effected by the choice of the salt used as a phosphate source. ${ }^{4}$ In the case of calcium carbonate, the co-incorporation of alkali ions, when formed at low super saturation, is well known and has been

\footnotetext{
${ }^{a}$ Max Planck Institute of Colloids and Interfaces, Potsdam-Golm Science Park,

14424 Potsdam, Germany. E-mail: luca.bertinetti@mpikg.mpg.de

${ }^{b}$ School of Physics and Astronomy, Queen Mary University of London,

Mile End Road, E1 4NS London, UK

${ }^{c}$ Department of Chemistry and iNANO, Aarhus University, DK-8000 Aarhus C, Denmark

$\dagger$ Electronic supplementary information (ESI) available. See DOI: 10.1039/c9cp02437a
}

suggested as a paleoceanographic proxy for estimating the salinity levels in ancient oceans. ${ }^{5-7}$ This effect is described in detail by Okumura et $a .^{7}$ by precipitating calcite under near equilibrium conditions over several weeks. The authors showed that the amount of $\mathrm{M}^{+}(\mathrm{M}=\mathrm{Li}, \mathrm{Na}, \mathrm{K}$ or $\mathrm{Rb})$ incorporated into calcite increased with increased initial concentration and smaller ion size, and was affected by the presence of other divalent ions like $\mathrm{Mg}^{2+}$. While these effects at equilibrium are well described, the effects of alkali metal ions on the formation of the amorphous phases under fast kinetics conditions, to the best of our knowledge, have never been considered.

In this study we have examined the co-incorporation of alkali counter ions into the metastable ACC phase using $\mathrm{M}_{2} \mathrm{CO}_{3}\left(\mathrm{M}=\mathrm{Li}^{+}, \mathrm{Na}^{+}, \mathrm{K}^{+}\right.$and $\left.\mathrm{Rb}^{+}\right)$as a carbonate source. We found that the larger ions exhibit increased incorporation into ACC.

Kinetic effects were examined during the thermal induced crystallization of ACC using TGA/DSC and during crystallization in solution with time resolved PXRD. ${ }^{8}$ We could show that the crystallization temperature $\left(T_{\mathrm{c}}\right)$ can be shifted by as much as $200{ }^{\circ} \mathrm{C}$, depending on the $\mathrm{M} /(\mathrm{M}+\mathrm{Ca})$ ratio. No kinetic effects were observed in solution related to the ACC phase but the formation rate of calcite was faster with increasing size of the counter ion. 


\section{Materials and methods}

\section{Materials synthesis}

ACC was synthesized as in our previous work, ${ }^{9}$ by rapid mixing of $20 \mathrm{~mL}$ of $1 \mathrm{M} \mathrm{CaCl}_{2}\left(\mathrm{CaCl}_{2} \cdot 2 \mathrm{H}_{2} \mathrm{O} \geq 99 \%, \mathrm{MgCl}_{2} \cdot 6 \mathrm{H}_{2} \mathrm{O}\right.$ 99-102\%, Sigma Aldrich) solution with $480 \mathrm{~mL}$ of $\mathrm{M}_{2} \mathrm{CO}_{3}$ with $\mathrm{M}=\mathrm{Li}^{+}, \mathrm{Na}^{+}$, $\mathrm{K}^{+}$and $\mathrm{Rb}^{+}\left(\mathrm{Li}_{2} \mathrm{CO}_{3}>99.0 \%, \mathrm{Rb}_{2} \mathrm{CO}_{3} 99 \%\right.$ Alfa Aesar, $\mathrm{Na}_{2} \mathrm{CO}_{3}$. $10 \mathrm{H}_{2} \mathrm{O} 99.999 \%, \mathrm{~K}_{2} \mathrm{CO}_{3}>99.0 \%$, Sigma Aldrich) to get an initial concentration of 5-150 mM for both the carbonate and calcium ions. 10 seconds after mixing the solution was filtered, after which the solid was washed with cold ethanol (99.8\%, Sigma Aldrich) and dried in a vacuum desiccator for a minimum of $24 \mathrm{~h}$ to remove excess ethanol.

\section{ICP-OES}

The $\mathrm{Ca}^{2+}, \mathrm{Li}^{+}, \mathrm{Na}^{+}, \mathrm{K}^{+}$, and $\mathrm{Rb}^{+}$content was determined by ICP using a PerkinElmer optima 8000 ICP-OES spectrometer (PerkinElmer, Waltham, MA, US). Final results were averaged using 3 measurements.

\section{TGA-DSC}

Thermogravimetric analysis was performed on a TGA/DSC (SENSYS evo TGA-DSC, SETARAM instrumentation, Caluire, France). Samples were placed in a corundum crucible and heated from 25-500 ${ }^{\circ} \mathrm{C}$ at $2{ }^{\circ} \mathrm{C} \min ^{-1}$. The crystallization temperature $\left(T_{\mathrm{c}}\right)$ was determined using the peak maximum of the first exothermic peak in the DSC signal using the inbuilt peak fitting routine in the Setaram software.

\section{PXRD and Rietveld refinement}

Synchrotron X-ray diffraction experiments were carried out at the $\mu$-Spot beamline (BESSY II, Helmholtz-Zentrum Berlin) using a multilayer monochromator and a wavelength of $0.826 \AA$. Two-dimensional (2D) scattering patterns were collected using a MarMosaic CCD detector (Rayonix L.L.C., Evanston, IL, USA). Radial integration of the 2D scattering patterns was performed using software Fit2D. ${ }^{10}$ The reactions were carried out in a modified setup base in the stopped-flow setup of Ibsen et al. ${ }^{8}$ The setup was modified to have a continuous flow to avoid potential diffraction spots from large single crystals resting in the beam. ${ }^{11}$ Diffractograms were measured every 10 seconds (5 second exposure +5 second detector read out) and Rietveld refinement was carried out in GSAS $^{12}$ using Multiref. ${ }^{13}$ The structural models of vaterite ${ }^{14}$ and calcite ${ }^{15}$ were used to calculate the Bragg peaks. Scale factor and unit cell parameters were refined for every time point for both phases and for vaterite an anisotropic peak broadening assigned to crystallite size effects was refined as well. The background was modelled using a Chebyshev polynomial.

\section{Results}

ACC samples were synthesised using Li-, Na-, K- and Rb-carbonate as a carbonate source with an initial concentration ranging from $5 \mathrm{mM}$ to $150 \mathrm{mM}$ with a $\mathrm{Ca}^{2+} / \mathrm{CO}_{3}{ }^{2-}$ ratio of $1 / 1$. A total of 32 samples were synthesized and the amorphous nature of the samples was confirmed using PXRD data (Fig. S1, ESI $\dagger$ ). At $5 \mathrm{mM}$, using $\mathrm{Rb}$ and $\mathrm{K}$-carbonate, calcite/vaterite mixtures were obtained and amorphous samples could not be isolated under these conditions. The remaining 30 samples were all amorphous.

To determine the co-incorporation of the counter ions, inductively coupled plasma-optical emission spectroscopy (ICP-OES) was used and from this the $\mathrm{M}^{+} /\left(\mathrm{M}^{+}+\mathrm{Ca}^{2+}\right)$ ratio $\left(\mathrm{M}^{+}=\mathrm{Li}^{+}, \mathrm{Na}^{+}, \mathrm{K}^{+}\right.$and $\left.\mathrm{Rb}^{+}\right)$was determined (Fig. 1). For all the samples, the reaction was made well below the solubility limit for $\mathrm{M}_{2} \mathrm{CO}_{3}$, except for $\mathrm{Li}_{2} \mathrm{CO}_{3}$, which has a solubility limit close to $150 \mathrm{mM}$ (Table S1, ESI $\dagger$ ). The $\mathrm{M}^{+} /\left(\mathrm{M}^{+}+\mathrm{Ca}^{2+}\right)$ ratio showed an increase with increasing initial concentration, similar to what is observed for calcite, but a decrease with smaller ion size, opposite of what is measured for the crystalline system. ${ }^{7}$ Considering that ions with higher $\mathrm{M}_{2} \mathrm{CO}_{3}$ salt solubility (Table $\mathrm{S} 1, \mathrm{ESI} \dagger$ ) incorporate less into ACC, the observed opposite trend suggests that kinetics effects play a major role in alkali ion incorporation during precipitation.

To understand the effect that these ions have on the stability of the synthesised ACC, the samples were thermally crystallized during TGA-DSC measurements (Fig. 2 and Fig. S2, ESI $\dagger$ ). In a typical run, two peaks in the DSC signal can be observed. One endothermic peak at $100{ }^{\circ} \mathrm{C}$, a characteristic of water loss and the second, an exothermic peak at $150-350{ }^{\circ} \mathrm{C}$, a characteristic of ACC crystallization. ${ }^{1}$ The temperature at which this second peak occurs defines the crystallization temperature $\left(T_{\mathrm{c}}\right)$, which varied significantly with the $\mathrm{M}^{+} /\left(\mathrm{M}^{+}+\mathrm{Ca}^{2+}\right)$ ratio. In the $\mathrm{Li}$ and Na co-incorporated samples we observed a two stage increase in $T_{\mathrm{c}}$, an initial increase from $\sim 150{ }^{\circ} \mathrm{C}$ to $\sim 200{ }^{\circ} \mathrm{C}$ followed by a plateau starting at $1 \mathrm{~mol} \%$. This initial increase can be explained by the particle size effect as described by Zou et al. ${ }^{1}$ as it coincides with a decrease in particle size between the samples made at an initial concentration of 5-20 mM (Fig. S3, $\mathrm{ESI} \dagger)$. The second increase appears at $\mathrm{M} /(\mathrm{M}+\mathrm{Ca})$ above $2 \mathrm{~mol} \%$ and $2.5 \mathrm{~mol} \%$ for $\mathrm{Li}$ and $\mathrm{Na}$ containing samples respectively and cannot be related to particle size, as the latter is constant for samples produced at that concentration. This suggests that $\mathrm{Li}$ and Na ions have no effect on ACC stability if incorporated in a low amount (below $2 \mathrm{~mol} \%$ ). However, over $2-2.5 \mathrm{~mol} \%$, they clearly affect the thermal stability of ACC, as $T_{\mathrm{c}}$ increases gradually with an increasing amount of $\mathrm{Li}$ and $\mathrm{Na}$. In the $\mathrm{K}$ and $\mathrm{Rb}$ containing samples, no plateau is observed suggesting

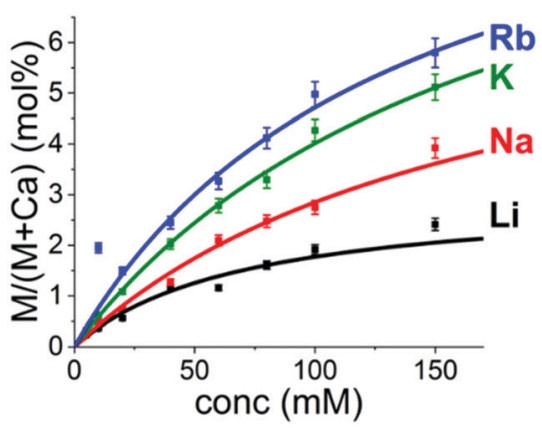

Fig. $1 M /(M+C a)$ ratio $v s$. initial concentration after extraction using Li- (black), Na- (red), K- (green) and Rb- (blue) carbonate as a carbonate source. 

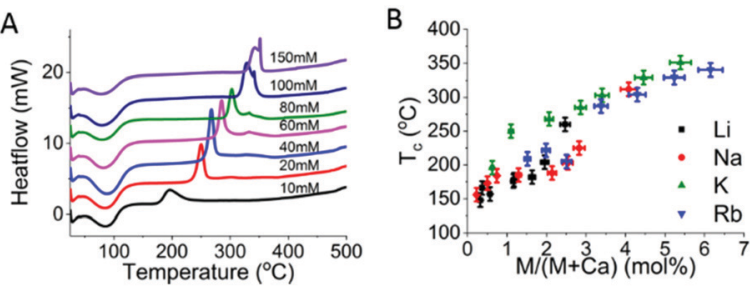

Fig. 2 (A) Typical DSC measurements of ACC made using $\mathrm{K}_{2} \mathrm{CO}_{3}$ at various concentrations showing two peaks, an endothermic peak obtained at $100{ }^{\circ} \mathrm{C}$ from water evaporation and an exothermic peak obtained by crystallization resulting in calcite. ${ }^{1}$ (B) The crystallization temperature for samples made using Li- (black), Na- (red), K- (green) and Rb- (blue) carbonate.

that, already at small ion contents, their stabilising effects will dominate over particle size effects.

To examine the crystallization process in solution, time resolved in solution PXRD was used (Fig. 3A)..$^{8,11}$ As this involves measuring a solid phase in a liquid, to have enough signal to overcome the large diffuse scattering of the solution (Fig. S4, ESI $\dagger$ ), a relatively high concentration of the solid is required. This could be achieved only at a large starting salt concentration of $1 \mathrm{M}$. Because of this, $\mathrm{Li}_{2} \mathrm{CO}_{3}$ could not be included as a carbonate source, due to its low solubility. By examining the background intensity and peak heights over time, a clear sequence of the reaction could be determined. An initial decrease in the diffuse scattering (Fig. S5A, ESI $\dagger$ ) suggests the initial formation of ACC, even before the first measurement was taken, followed by a concurrent dissolution of ACC and an increase in the calcite and vaterite peaks (Fig. 3 and Fig. S5B, ESI $\dagger$ ), with vaterite being the dominant phase as expected. ${ }^{16}$ No difference was observed in the life time of ACC or in the growth rate of the vaterite phase while using different carbonate sources (Fig. S5, ESI $\dagger$ ). Also, the nucleation time does not differ significantly compared to experiments performed at low concentrations. ${ }^{1}$ This suggests that the co-incorporated
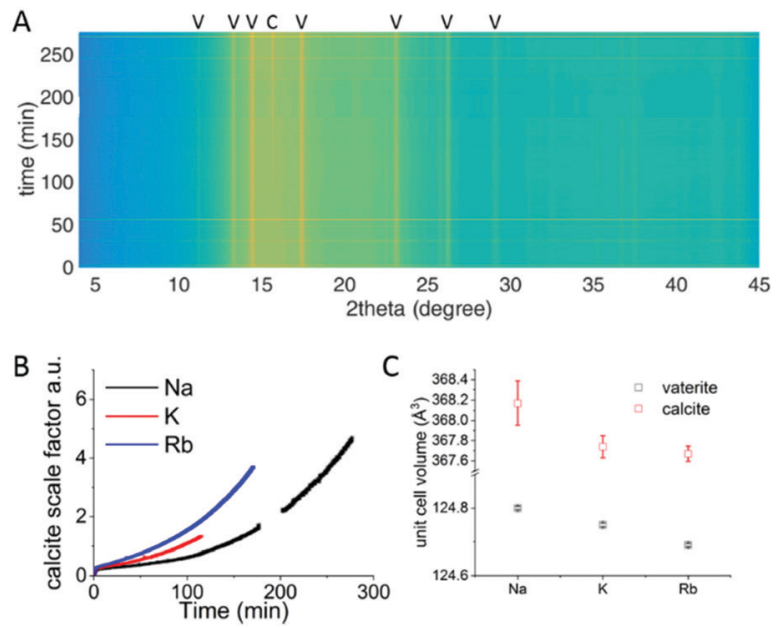

Fig. 3 (A) Time resolved PXRD, with $v$ and $c$ denoting the main calcite and vaterite peaks. Examples of Rietveld fits are shown in Fig. S4 (ESI†). (B) Scale factor of the calcite phase extracted using Rietveld refinement and (C) unit cell parameters 105 minutes after mixing. ions do not influence the stability of ACC in solution. Probably, this is because the crystallization occurs via a dissolutionreprecipitation mechanism ${ }^{17}$ and the alkali ions dissolve in the process. However, there was a large difference in the calcite growth rate when using different carbonate sources (Fig. 3B), with calcite forming in the presence of $\mathrm{Rb}$ showing the fastest growth rate and that in the presence of Na showing the slowest growth rate. Overall, these data indicate that the incorporation of alkali ions may slow down the growth of the calcite crystals but not that of the vaterite crystals.

Examination of the unit cell volume for calcite and vaterite (Fig. 3C and Fig. S5D, E, ESI $\dagger$ ) showed a small but consistent drop in unit cell volume with increasing ion size of the alkali metal ion. As a smaller unit cell volume would indicate either smaller ion size or lower concentration of the foreign ion, this suggests that the co-incorporation in the crystalline phase is the highest for $\mathrm{Na}$ and lowest for $\mathrm{Rb}$, consistent with the results of Okumura et al. ${ }^{7}$

\section{Conclusion}

By precipitating ACC in the presence of various alkali metal ions, we observed that large monovalent cations incorporate more than smaller ones into the initial amorphous phase. This trend is opposite to that observed in the crystalline phase, indicating that the co-incorporation is largely affected by the kinetics conditions of the precipitation reaction. The co-incorporated ions were further shown to have a strong stabilizing effect during thermally induced crystallization, as they could increase $T_{\mathrm{c}}$ by as much as $200{ }^{\circ} \mathrm{C}$. When crystalizing in solution no stabilizing effect was observed on the transformation of ACC to vaterite, but the growth rate of calcite from vaterite did decrease with decreasing size of the counter ions. The findings of this work highlight the role of the alkali metal ions during ACC precipitation and transformation, can help guide biomimetic material synthesis and bear important implications for understanding biomineralization strategies.

\section{Conflicts of interest}

There are no conflicts to declare.

\section{Note from RSC Publishing}

This article was originally published with incorrect page numbers. This is the corrected, final version. The Royal Society of Chemistry apologises for these errors and any consequent inconvenience to authors and readers.

\section{Acknowledgements}

The authors would like to thank Stefan Siegel and Chenghao Li for their support during the experiment at the $\mu$ spot beamline at Bessy-II, Helmholtz-Zentrum Berlin. Additional thanks go to Jeannette Steffens for help with the ICP-OES measurements. 
The research was supported by a German Research Foundation grant within the framework of the Deutsch-Israelische Projektkooperation DIP. HB gratefully acknowledges affiliation with the center for integrated materials research (iMAT) at Aarhus University. Open Access funding provided by the Max Planck Society.

\section{References}

1 Z. Zou, L. Bertinetti, Y. Politi, A. C. S. Jensen, S. Weiner, L. Addadi, P. Fratzl and W. J. E. M. Habraken, Opposite Particle Size Effect on Amorphous Calcium Carbonate Crystallization in Water and during Heating in Air, Chem. Mater., 2015, 27(12), 4237-4246.

2 L. Addadi, S. Raz and S. Weiner, Taking Advantage of Disorder: Amorphous Calcium Carbonate and Its Roles in Biomineralization, Adv. Mater., 2003, 15(12), 959-970.

3 S. Mann, Biomineralization: Principles and Concepts in Bioinorganic Materials Chemistry, Oxford University Press, 2001, vol. 5.

4 C. J. S. Ibsen, H. Leemreize, B. F. Mikladal, J. Skovgaard, M. Bremholm, J. R. Eltzholtz, B. B. Iversen and H. Birkedal, Alkali Counterions Impact Crystallization Kinetics of Apatite Nanocrystals from Amorphous Calcium Phosphate in Water at High pH, Cryst. Growth Des., 2018, 18(11), 6723-6728.

5 J. C. Wit, L. J. de Nooijer, M. Wolthers and G. J. Reichart, A novel salinity proxy based on Na incorporation into foraminiferal calcite, Biogeosciences, 2013, 10(10), 6375-6387.

6 Y. Kitano, M. Okumura and M. Idogaki, Incorporation of sodium, chloride and sulfate with calcium carbonate, Geochem. J., 1975, 9(2), 75-84.

7 M. Okumura and Y. Kitano, Coprecipitation of alkali metal ions with calcium carbonate, Geochim. Cosmochim. Acta, 1986, 50(1), 49-58.
8 C. J. S. Ibsen and H. Birkedal, Influence of poly (acrylic acid) on apatite formation studied by in situ X-ray diffraction using an X-ray scattering reaction cell with high-precision temperature control, J. Appl. Crystallogr., 2012, 45(5), 976-981.

9 A. C. S. Jensen, S. Imberti, S. F. Parker, E. Schneck, Y. Politi, P. Fratzl, L. Bertinetti and W. J. E. M. Habraken, Hydrogen Bonding in Amorphous Calcium Carbonate and Molecular Reorientation Induced by Dehydration, J. Phys. Chem. C, 2018, 122(6), 3591-3598.

10 A. Hammersley, FIT2D: an introduction and overview. European Synchrotron Radiation Facility Internal Report ESRF97HA02T 1997, 68.

11 A. C. S. Jensen, M. Hinge and H. Birkedal, Calcite Nucleation on the Surface of PNIPAM-PAAc Micelles Studied by Time Resolved in situ PXRD, CrystEngComm, 2015, 17(36), 6940-6946.

12 B. Toby, EXPGUI, a graphical user interface for GSAS, J. Appl. Crystallogr., 2001, 34(2), 210-213.

13 S. Frolich and H. Birkedal, MultiRef: software platform for Rietveld refinement of multiple powder diffractograms from in situ, scanning or diffraction tomography experiments, J. Appl. Crystallogr., 2015, 48(6), 2019-2025.

14 S. Kamhi, On the Structure of Vaterite CaCO3, Acta Crystallogr., 1963, 16(8), 770-772.

15 D. Graf, Crystallographic Tables for the Rhombohedral Carbonates, Am. Mineral., 1961, 46(11-2), 1283-1316.

16 J. D. Rodriguez-Blanco, S. Shaw and L. G. Benning, The kinetics and mechanisms of amorphous calcium carbonate (ACC) crystallization to calcite, viavaterite, Nanoscale, 2011, 3(1), 265-271.

17 A. J. Giuffre, A. C. Gagnon, J. J. De Yoreo and P. M. Dove, Isotopic tracer evidence for the amorphous calcium carbonate to calcite transformation by dissolution-reprecipitation, Geochim. Cosmochim. Acta, 2015, 165, 407-417. 